\title{
O uso de atividades experimentais como recurso para educação ambiental: um caso de reaproveitamento hídrico no âmbito escolar
}

The use of experimental activities as a resource for environmental education: a case of water reuse at school

El uso de actividades experimentales como recurso para la educación ambiental: un caso de reutilización del agua en la escuela

Joselia Cristina Siqueira da Silva ORCID: https://orcid.org/0000-0003-2448-9886 Universidade Federal do Paraná, Brasil E-mail: jcristinaquimica@gmail.com Gilmene Bianco

ORCID: https://orcid.org/0000-0002-2654-5370 Universidade Federal do Espírito Santo, Brasil E-mail: gilmeneb@yahoo.com.br

Dieison Prestes da Silveira

ORCID: https://orcid.org/0000-0002-8446-4157 Universidade Federal do Paraná, Brasil E-mail: dieisonprestes@gmail.com Rodrigo Da Vitória Gomes

ORCID: https://orcid.org/0000-0002-7171-695X Universidade Federal do Paraná, Brasil

E-mail: rodrigodavitoriagomes@gmail.com

Deivid Jonas Silva da Veiga

ORCID: https://orcid.org/0000-0002-1625-0560 Universidade de Cruz Alta, Brasil E-mail: deividveiga96@gmail.com Lielle Serafim

ORCID: https://orcid.org/0000-0003-2737-5729 Universidade Federal do Espírito Santo, Brasil E-mail: lielle.serafim@gmail.com

\begin{abstract}
Resumo
Com o aumento do desperdício de água e a poluição do meio ambiente, a atividade humana passou a ser uma grande geradora de resíduos, acarretando inúmeras consequências ambientais. A escassez dos recursos hídricos é uma das principais consequências encontradas no nosso cenário atual. Tendo em vista a escassez da água, diversas ações alternativas para o tratamento de águas residuais estão sendo desenvolvidas. Uma técnica que pode favorecer a descontaminação da água é a eletrofloculação, que causa a aglutinação de impurezas, por meio de reações de oxirredução. Partindo desse pressuposto, o objetivo principal deste trabalho é analisar como o desenvolvimento de atividades experimentais no ensino de química pode favorecer a conscientização para preservação de recursos hídricos. A pesquisa contemplou 28 alunos matriculados na $2^{\mathrm{a}}$ série do Ensino Médio de uma escola pública estadual de Colatina-ES no ano de 2019, apresentando metodologia com abordagem qualitativa e experimental. Os dados foram analisados por meio do Método de Análise Observacional, permitindo-nos concluir que a utilização da experimentação no processo de ensino quando atrelada a Educação Ambiental pode gerar incentivo à curiosidade e a pesquisa, potencializando saberes a relação homem-ambiente.
\end{abstract}

Palavras-chave: Educação ambiental; Reaproveitamento da água; Atividades experimentais.

\begin{abstract}
With the increase in water waste and pollution of the environment, human activity has become a major generator of waste, causing numerous environmental consequences. The scarcity of water resources is one of the main consequences found in our current scenario. In view of the scarcity of water, several alternative actions for the treatment of wastewater are being developed. One technique that can favor the decontamination of water is electroflocculation, which causes the agglutination of impurities through oxidation reactions. Based on this assumption, the main objective of this work is to analyze how the development of experimental activities in the teaching of chemistry can promote awareness for the preservation of water resources. The research included 28
\end{abstract}


students enrolled in the 2nd grade of high school at a state public school in Colatina-ES in 2019, presenting a methodology with a qualitative and experimental approach. The data were analyzed using the Observational Analysis Method, allowing us to conclude that the use of experimentation in the teaching process when linked to Environmental Education can generate incentives to curiosity and research, enhancing knowledge of the relationship between man and the environment.

Keywords: Environmental education; Water reuse; Experimental activities.

\section{Resumen}

Con el aumento del desperdicio de agua y la contaminación del medio ambiente, la actividad humana se ha convertido en un importante generador de desechos, provocando numerosas consecuencias ambientales. La escasez de recursos hídricos es una de las principales consecuencias encontradas en nuestro escenario actual. Ante la escasez de agua, se están desarrollando varias acciones alternativas para el tratamiento de aguas residuales. Una técnica que puede favorecer la descontaminación del agua es la electrofloculación, que provoca la aglutinación de impurezas mediante reacciones de oxidación. A partir de este supuesto, el objetivo principal de este trabajo es analizar cómo el desarrollo de actividades experimentales en la enseñanza de la química puede promover la conciencia para la preservación de los recursos hídricos. La investigación incluyó a 28 estudiantes matriculados en el $2^{\circ}$ grado de secundaria en una escuela pública estatal en Colatina-ES en 2019, presentando una metodología con enfoque cualitativo y experimental. Los datos fueron analizados mediante el Método de Análisis Observacional, permitiéndonos concluir que el uso de la experimentación en el proceso de enseñanza cuando se vincula a la Educación Ambiental puede generar incentivos a la curiosidad y la investigación, potenciando el conocimiento de la relación entre el hombre y el medio ambiente.

Palabras clave: Educación ambiental; Reutilización de agua; Actividades experimentales.

\section{Introdução}

A água é considerada um elemento essencial para a vida de um indivíduo. Sua existência é vital para o corpo humano e nas diversas situações do cotidiano que exigem a utilização deste recurso. O Brasil é considerado um dos ambientes com maior oferta de água doce do mundo, mas a concentração desse recurso fornecido à população é de sigual (Tundisi, 2003).

De acordo com Barros (2010), 89\% do total de água doce nas regiões norte e centro-oeste do Brasil é utilizada por $14,5 \%$ da população total, enquanto as regiões nordeste, sudeste e sul onde estão distribuídas 85,5\% da população do país, há disponível apenas $11 \%$ de água. Esses dados indicam distribuição desigual da água. Nesse sentido, o Brasil possui áreas abundantes de água doce com poucos moradores, e em contrapartida, regiões populosas carecem de recursos hídricos.

Guimarães (2006 apud Silva, 2009) afirma que é necessária uma reflexão sobre os problemas ambientais presentes na sociedade. Para o autor, somente o conhecimento da existência desses problemas não proporciona modificações ao meio ambiente.

A conscientização sobre as crises hídricas e as ações locais sobre os recursos hídricos são essenciais para a restauração, conservação e preservação da água. O papel do educador é essencial para auxiliar os alunos à compreensão da necessidade de cautela de hábitos e atitudes em relação ao uso racional da água. Almeja-se que o professor tenha uma formação adequada sobre o tema, de forma que através do processo de ensino o mesmo possa possibilitar ao educando adquirir conhecimentos, competências e atitudes que sejam favoráveis ao meio ambiente (Carvalho, 2008).

Carvalho (2008) relata a necessidade de a Educação Ambiental estar presente nas discussões sobre a água no âmbito escolar, para que os educandos adquiram uma nova "mentalidade ecológica" diante das crises hídricas. Tristão (2004) explana a importância de se refletir sobre a formação dos professores para atuarem pensando na conscientização ambiental. A autora relata que muitos dos professores não tiveram durante a sua formação o contato com discussões teóricas e metodológicas que os levassem a desenvolver trabalhos na área da Educação Ambiental. O desenvolvimento da Educação Ambiental no processo de ensino deve ocorrer de forma integrada, contínua e permanente nos diversos níveis de ensino.

Brasil (1999, p. 03) relata a importância dos currículos concernirem acerca da Educação Ambiental:

Art. 11. A dimensão ambiental deve constar dos currículos de formação de professores, em todos os níveis e em todas as disciplinas. Parágrafo único. Os professores em atividade devem receber formação complementar em suas áreas de 
atuação, com o propósito de atender adequadamente ao cumprimento dos princípios e objetivos da Política Nacional de Educação Ambiental.

Tratando-se de Educação Ambiental no contexto escolar, Penteado (2012) defende a ideia de que o meio ambiente deve receber uma constante atenção, relatando a necessidade de modificar a conjuntura de se realizar os trabalhos escolares que contemplem o meio ambiente de informativo que é apenas superficial, para o formativo sendo consciente e atuante.

A atividade humana é uma grande geradora de resíduos. Corantes, óleos, graxas e muitos outros subprodutos acarretam diversos problemas ao meio ambiente. Em vista da escassez dos recursos hídricos disponíveis, diversas alternativas e novas tecnologias têm sido desenvolvidas para o tratamento desses compostos. Uma técnica simples e eficaz em seus resultados é a eletrofloculação (Neto, 2011).

Eletrofloculação é um processo eletrolítico que envolve a desestabilização de poluentes emulsificados, ou em suspensão, em meio aquoso (Neto, 2011). O tratamento eletroquímico tem se mostrado um processo que oferece grande eficiência para remoção de matéria suspensa em efluentes, utilizando equipamentos simples e compactados para o controle e a operação do processo. A floculação consiste em aglomerar as partículas utilizando as forças de Van der Waals (força de atração entre as moléculas), dando origem a flocos de granulometria maiores em comparação as partículas isoladas (Carvalho \& Souza, 2015).

A eletrofloculação é um processo que utiliza corrente elétrica, envolvendo reatores eletroquímicos, nos quais são coagulantes por oxidação eletrolítica de um material apropriado no ânodo, como por exemplo, o ferro. A geração de íons metálicos ocorre no ânodo, enquanto a do gás hidrogênio ocorre no cátodo (Gobbi, 2013).

Partindo da necessidade de contextualização no ensino e a conscientização da comunidade escolar para a reutilização de água, esse artigo visa obter reflexão acerca da seguinte temática: como o uso de atividades experimentais, podem favorecer uma aprendizagem potencialmente significativa e gerar a conscientização para preservação de recursos hídricos?

\section{Metodologia}

Para essa atividade o tema abordado foi à escassez da água em tempos de seca, processo de separação de misturas, reaproveitamento dos recursos hídricos e o processo de oxirredução do ferro. Sendo esses conteúdos desenvolvidos com as turmas de $2^{\mathrm{a}}$ série do Ensino Médio de uma escola pública estadual localizada no município de Colatina no estado do Espírito Santo. A professora regente propôs ao grupo de alunos a elaboração de um sistema que a partir da oxidação do ferro pudesse gerar energia necessária para contribuir com floculação de substâncias impuras na água, e a viabilizando para reúso doméstico.

Foram disponibilizadas 8 aulas da disciplina de Química durante o período de 12/08/2019 a 05/09/2019 para a realização dessa atividade. Iniciou-se o primeiro momento pedagógico com o levantamento de noções básicas sobre processo de separação de misturas e reaproveitamento de recursos hídricos. Posteriormente a esse momento, foi realizada uma aula de revisão sobre esses assuntos no intuito de atualizar possíveis situações outrora esquecidas. No total, essa etapa contou com a disponibilização de duas aulas para a discussão inicial dos temas abordados. Esse procedimento de análise dos conhecimentos prévios pressupõe, conforme Carvalho (2009), que o processo de ensino e aprendizagem se desenvolva partindo das experiências e vivências dos próprios alunos, ao valorizar e considerar conceitos pré-existentes na sua estrutura cognitiva.

O segundo momento pedagógico foi iniciado com a aula expositiva e com explanação conceitual dos conteúdos envolvendo a oxidação do ferro. Por se tratar de um conceito novo, foram disponibilizadas duas aulas para a realização dessa parte da pesquisa.

O terceiro momento pedagógico foi desenvolvido com a construção do sistema eletroquímico. A turma foi dividida em 7 grupos de 4 alunos cada, dessa forma todos os integrantes do grupo participariam ativamente do processo experimental. Para essa atividade a professora disponibilizou quatro aulas, tendo em vista que as aulas iniciais não obtiveram total êxito 
devido a falta de alguns matérias entre os grupos e devido as tentativas de geração de energia através de distintas baterias até concluir qual bateria de fato suportaria todo o processo sem perder a energia da reação. A água utilizada pelos alunos durante o processo de eletrofloculação era oriunda da lavagem dos panos disponibilizados para a limpeza do ambiente escolar.

No que se refere a estruturação metodológica dessa pesquisa, evidenciamos que à abordagem viabiliza uma atividade qualitativa, haja vista que o objetivo final não foi a representatividade numérica, e sim o aprofundamento e compreensão do objeto de estudo (Gerhardt \& Silveira, 2009).

Quanto à natureza, a atividade foi experimental, pois objetivou "gerar conhecimentos para aplicação prática, dirigidos à solução de problemas específicos, envolvendo verdades e interesses locais" (Gerhardt \& Silveira, 2009, p. 35).

Os dados foram analisados por meio do Método de Análise Observacional, o mesmo fundamenta-se em procedimentos de natureza sensorial, no qual o pesquisador é emergido ao mundo dos fenômenos empíricos, podendo assim captar com precisão os aspectos essenciais e acidentais desses fenômenos (Fachin, 2017). Ressalta-se que a atividade não teve teor avaliativo, não sendo atribuído questionários e nem qualquer tipo de pontuação durante todo o processo de aplicação da experimentação.

\section{Materiais e métodos}

Ao desenvolver a atividade, foi solicitado aos alunos o maior uso de substâncias simples e que poderiam ser encontrados na própria residência. Os materiais de difícil compra, ou não encontrados na residência dos estudantes foram solicitados ao professor e alguns materiais cedidos pela escola. No Quadro 1 a seguir, relata-se os materiais utilizados para a montagem e produção do sistema eletroquímico.

Quadro 1. Materiais utilizados para produção do sistema eletroquímico.

\begin{tabular}{|l|l|}
\hline 1 bateria de $18 \mathrm{~V}$ & 2 fios de cobre \\
\hline 2 pregos & Filtro de papel \\
\hline Sal de cozinha & Funil \\
\hline Garras do tipo "jacaré” & 2 béqueres de $50 \mathrm{~mL}$ \\
\hline
\end{tabular}

Fonte: Autores (2019)

A escola cedeu os béqueres e funis utilizados na experimentação, oriundos do laboratório de Química. A professora regente disponibilizou as baterias de $18 \mathrm{~V}$, os pregos, as garras do tipo "jacaré", os fios de cobre e os filtros de papel. Os alunos foram responsáveis por ceder o sal de cozinha durante o experimento.

Os pregos, as garras de apoio e os fios de cobre podem ser encontrados em qualquer loja de materiais de construção, enquanto a bateria de $18 \mathrm{~V}$ encontra-se em drogarias e farmácias. Já o filtro de papel é disponibilizado em qualquer supermercado, independente da região.

\section{Contribuições das Atividades Experimentais ao Ensino de Química}

As aulas experimentais podem ser desenvolvidas com diferentes objetivos, as mesmas tendem a abordam o caráter motivador e investigador do educando. Embora o contexto escolar entre a interação aluno-professor seja feita de forma tradicional, o trabalho em grupo é frequentemente apontado como uma estratégia de ensino que favorece a socialização dos alunos, influenciando os a ouvir e respeitar a opinião dos colegas (Galiazzi \& Gonçalves, 2004).

Nas aulas experimentais, especialmente naquelas em que os alunos desenvolvem em grupo as atividades propostas, uma série de habilidades e competências podem ser favorecidas: divisão de tarefas, responsabilidade individual e com o grupo, 
negociação de ideias e diretrizes para a solução dos problemas. Carvalho (2013) ressalta a necessidade de o professor ficar atento ao planejamento das atividades em grupo e a observação do andamento do trabalho durante as aulas. Não basta reunir grupos, é necessário ter embasamento para tal processo.

A atividade experimental em sala de aula permite a articulação de fenômenos e teorias, se conectando a vivência do cotidiano do educando ao pensamento perspicaz e reflexivo da ciência (Silva et al., 2010)

Quando o aluno é instigado a pesquisar e a propor hipóteses para a solução de problemas ou a pensar e fornecer explicações para os fenômenos observados nos experimentos, automaticamente são estimulados a tomar decisões e expressar suas ideias para outras pessoas, oportunizando assim a formação social e capacidade de raciocínio (Galiazzi \& Gonçalves, 2004).

Hodson (1988) define a experimentação como um trabalho prático de aprendizagem, que permite o aluno construir novos entendimentos sobre o objeto estudado. Dentre as atividades experimentais citadas pelo autor, encontram-se: experiências na bancada de laboratório, simulações em computador, demonstrações feitas pelo professor, vídeos ou filmes, estudo de caso, debates, seminários, teatro científico, confecções de modelos, jogos didáticos e aulas de campo.

Atividades experimentais objetivam a transposição dos limites do ensino formal e descritivo, que se direcionam a um cenário interativo e estimulador. O trabalho prático viabiliza o encontro do sujeito com as particularidades do objeto de aprendizagem, é a existência de algo novo (Souza, 2011).

Embora muitos professores reconheçam a importância da experimentação, poucos utilizam essa metodologia. O ensino de química, em grande parte é limitado ao modelo tradicional de ensino, no qual há apenas a transmissão e recepção do aprendizado (Moreira, 2012).

Hodson (1988) considera que os professores não são preparados para trabalhar a Química em sala de aula. Alguns acabam se limitando a reproduzir um aprendizado tradicional, com pouquíssimos recursos pedagógicos. A prática pedagógica do professor revela suas concepções de ensino e de aprendizagem. Ao se deparar com professores que educam de forma tradicional, percebemos que os mesmos foram formados de forma tradicional.

\section{O Reaproveitamento de Água em Tempos de Seca, uma Conscientização Significativa ao Aprendizado}

A escassez de água tem conduzido à implantação de projetos alternativos de convivência com a seca que conduzam a melhorias sociais. Neste contexto, o reuso planejado de água apresenta-se como uma oportunidade de valorização da mesma na região. Por isso é necessário o desenvolvimento de maneiras de reutilização da água que precisam ser amplamente difundidas e implantadas o mais rápido possível em tudo e por todos, contribuindo assim para o desenvolvimento sustentável (Asano, 2002).

Dentro do processo de tomada de consciência de reúso, a escola é um ambiente de grande auxílio. A escola deve formar cidadãos críticos e conscientes. Sabe-se que o foco da escola é o aluno, o principal eixo da escolarização é a aprendizagem. Deve-se ensinar pensando em como o aluno aprende, e esse processo de construção do saber está ligado diretamente às teorias de aprendizagem. As teorias de aprendizagem estão fixadas em valores filosóficos, que procuram explicar como o indivíduo aprende. Ao olhar os diversos aportes teóricos que integram o processo de aprendizagem, devemos levar em conta o conhecimento que o educando já tenha se apropriado, o conhecimento prévio adquirido nos anos anteriores e no seu meio cultural. Diante disso, o professor passa a ter o papel de mediador das informações já adquiridas pelo aluno ao longo do ensino médio e começa a preparação para a introdução de um novo e fundamental conceito na vida escolar.

A introdução desse novo conceito está relacionada à Teoria da Aprendizagem Significativa, proposta por David Paul Ausubel. A qual afirma que é partindo de conteúdos que indivíduos já possuem na sua estrutura cognitiva, que a aprendizagem 
pode ocorrer. É por meio desses conteúdos prévios que novos conteúdos deverão ser introduzidos, modificando e criando novas significações àquelas preexistentes (Ausubel, Novak \& Hanesian, 1983).

Aprendizagem Significativa é, portanto, um processo por meio do qual uma nova informação é acoplada a uma estrutura cognitiva particular e específica, prévia, conhecida como subsunçor. Sendo que Ausubel diz: "o fator mais importante que influi na aprendizagem é aquilo que o aluno já sabe. Isto deve ser averiguado e o ensino deve depender desses dados" (Ausubel, Novak \& Hanesian, 1983, p. 66).

Segundo Ausubel (1983), é indispensável para que haja uma aprendizagem significativa, que os alunos se predisponham a aprender significativamente, surgindo então à necessidade de despertar no aluno o desejo, à vontade, o anseio pela aprendizagem. Como despertar no educando a predisposição a uma aprendizagem?

De acordo com Benite (2006), as diferentes ferramentas para o ensino de química, proporcionam além de pesquisas, algumas simulações que podem despertar grande interesse científico ao educando, proporcionando ao mesmo a chance de manipular ou até mesmo a confecção de materiais de uso científico.

Sobre esse assunto, Penin (2001, p. 37) afirma:

O acesso ao saber não mais seguirá apenas a ordem hierárquica e progressiva como geralmente é disposta na programação de uma disciplina ao longo das séries escolares. A tecnologia disponível, sobretudo através da internet, MS também em programas já existentes, como os de vídeo, possibilita diferentes formas de acesso ao saber [...]. Essas novas oportunidades de aprendizagem, se disponíveis aos alunos, provocam a necessidade de uma mudança profunda didática utilizada pelos professores. Mais do que seguir um programa, eles precisam relacionar e dar sentido a essa trama a que os alunos estão submetidos.

O papel do professor neste tipo de atividade é distinto. Sua função é essencialmente auxiliar os alunos na busca das explicações causais, negociar estratégias para resoluções de problemas, questionar as ideias dos alunos, incentivar a criatividade epistêmica em todas as etapas da atividade e mediar o grupo e as tarefas, intervindo nos momentos em que há indecisão, falta de clareza ou consenso.

\section{Estratégias Didático- Pedagógicas no Processo de Educação Ambiental}

Com o aumento do desperdício de água e a poluição do meio ambiente, a atividade humana passou a ser uma grande geradora de resíduos, acarretando inúmeras consequências ambientais. A escassez dos recursos hídricos é uma das principais consequências encontradas no nosso cenário atual. A poluição ambiental e o desperdício desenfreado de água têm colaborado para o desenvolvimento do período de seca em diversas regiões pelo país (Silva, 2009).

Em algumas regiões brasileiras como a região de Colatina no estado do Espírito Santo, a falta de água pode ser agravada e associada a poluição do Rio Doce, devido ao rompimento da barragem de minério de Fundão, localizada na região de Mariana- MG, pela mineradora Samarco, ocasionando um dos maiores desastres ambientais do país nos últimos anos.

A quantidade de lama proveniente do desastre acarretou no assoreamento do rio, que ao juntar com o período de seca sofrido pela região acaba por ocasionar a falta de água em vários pontos da cidade. Como, a região apesar de ser localizada no noroeste do estado, conta com mais de 80 escolas entre municipais e estaduais, a mesma passa a ser um grande cenário para a realização da tomada de consciência dos sujeitos nela inseridos para a necessidade de racionalização e combate ao desperdício desenfreado de recursos hídricos.

Tendo em vista essa escassez da água, diversas ações alternativas para o tratamento de águas resíduais estão sendo desenvolvidas. Uma técnica que pode favorecer a descontaminação da água é a eletrofloculação, que causa a aglutinação de impurezas, por meio de reações de oxirredução.

Com o intuito de contribuir com a prevenção do desperdício desnecessário da água, este trabalho viabilizou a criação 
de um sistema eletroquímico que possa descontaminar ou despoluir a água por meio da eletrofloculação, a fim de fazer a reutilização da mesma nas atividades cotidianas de limpeza, como lavagem de pátios, escadas, galpões e salas de aula. Ressalta-se que o sistema eletroquímico não deve ser construído no intuito de gerar água potável para consumo humano, mas, despoluir e descontaminar uma água inutilizada para a reutilização nos serviços gerais da escola.

\section{Resultados e Discussão}

A turma foi dividida em grupos, contendo quatro alunos em cada grupo. O intuito é que todos os alunos participassem efetivamente do processo de experimentação. Para a realização do processo de eletrofloculação, foram utilizados dois pregos de ferro, que atuaram como ânodo e cátodo da reação. Os pregos foram acoplados a um suporte que serviu de base da sustentação (garras tipo jacaré), e em cada eletrodo foi inserido uma única fonte de cerca de $18 \mathrm{~V}$. Em um dos béqueres foi adicionado cerca de $30 \mathrm{~mL}$ de água suja. Em seguida foi adicionado à solução cerca de $10 \mathrm{~g}$ de sal de cozinha (uma colher de sopa), a fim de facilitar a passagem de corrente elétrica. O suporte com os eletrodos foi posto no recipiente em contato com a solução e então a fonte de energia foi ligada. Após 20 minutos, a solução passou por um processo de filtração simples e estava pronta para o reúso doméstico.

A seguir, a Figura 1 apresenta imagem do processo de limpeza da água através da técnica de eletrofloculação.

Figura 1 - Processo de eletrofloculação e limpeza da água.

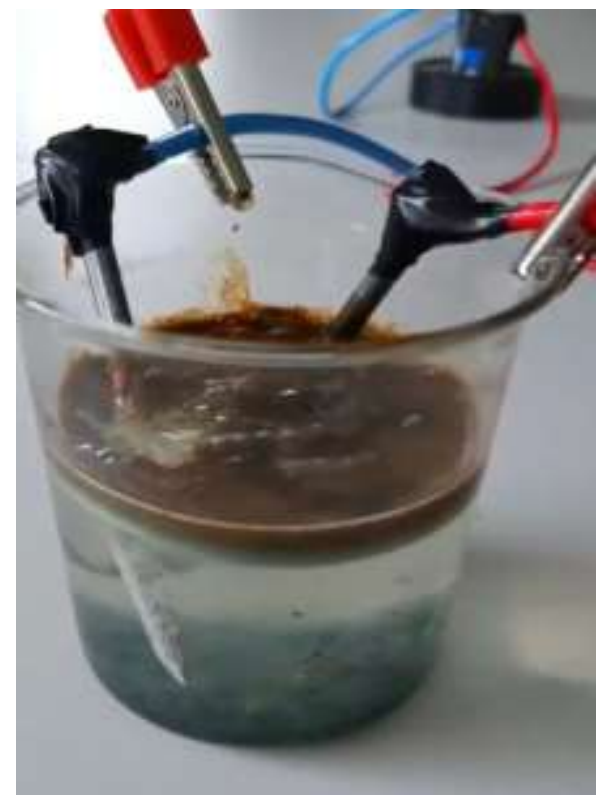

Fonte: Autores (2019).

Nesse momento ocorre a formação de bolhas de $\mathrm{H}_{2}$, ou seja, a liberação do gás hidrogênio ao redor do eletrodo que agiu como cátodo, além da formação do sólido hidróxido de sódio $(\mathrm{NaOH})$ a partir da reação. Com o passar do tempo e devido a positividade férrica, consegue-se neutralizar as impurezas coloidais carregadas negativamente presentes na água. A partir disso, as partículas de sujeira sofrem uma aglutinação formando flóculos sólidos de tamanho maior da solução que podem ser vistos através da decantação no fundo do recipiente (Cerqueira \& Marques, 2011).

O par de pregos constitui os eletrodos da reação. O eletrodo negativo é denominado ânodo e é responsável por fornecer os íons que reagem com a hidroxila da água, favorecendo a formação do hidróxido de ferro II:

$$
\mathrm{Fe}^{2+}(\mathrm{aq})+2 \mathrm{OH}^{-}(\ell) \rightarrow \mathrm{Fe}(\mathrm{OH})_{2}(\mathrm{~s})
$$


A partir dessa reação é notada a formação de uma base pouco solúvel que absorve os pigmentos dispersos na solução. Ao mesmo tempo, podem-se observar bolhas no outro eletrodo denominado de cátodo, que é o gás hidrogênio sendo liberado:

$$
2 \mathrm{H}_{2} \mathrm{O}(\ell)+2 \mathrm{e}^{-} \rightarrow \mathrm{H}_{2}(\mathrm{~g})+2 \mathrm{OH}^{-}(\ell)
$$

Ao final do experimento, o prego que atuou como ânodo se apresentará desgastado enquanto o cátodo sofrerá uma mudança de coloração devido a formação de $\mathrm{FeOH}_{2}$ (hidróxido de ferro II). Após a formação dos flóculos, será notada uma coloração mais límpida da água, no qual, os flóculos maiores formados podem, então, ser retirados do efluente e separados através da filtração. Após a filtração, os flóculos irão ficar retidos no filtro enquanto a solução irá se apresentar límpida (Cerqueira \& Marques, 2011).

Devido ao sucesso deste experimento na escola, então o mesmo foi escolhido para ser apresentado na IV Feira Estadual de Ciências e Engenharia do Espírito Santo durante a Semana Nacional de Ciência e Tecnologia de 2019. A Feira foi realizada durante os dias 23 e 24/10/2019 na cidade de Vila Velha no estado do Espírito Santo. Para a escolha de qual grupo apresentaria o projeto durante a feira estadual, a professora contou com a ajuda da supervisão escolar e alunos que se disponibilizaram a apresentar o projeto de forma clara e objetiva.

A Figura 2, apresenta a imagem dos alunos durante a realização da Semana Nacional de Ciência e Tecnologia de 2019.

Figura 2 - Imagem dos alunos durante a realização da Semana Nacional de Ciência e Tecnologia do ano de 2019.

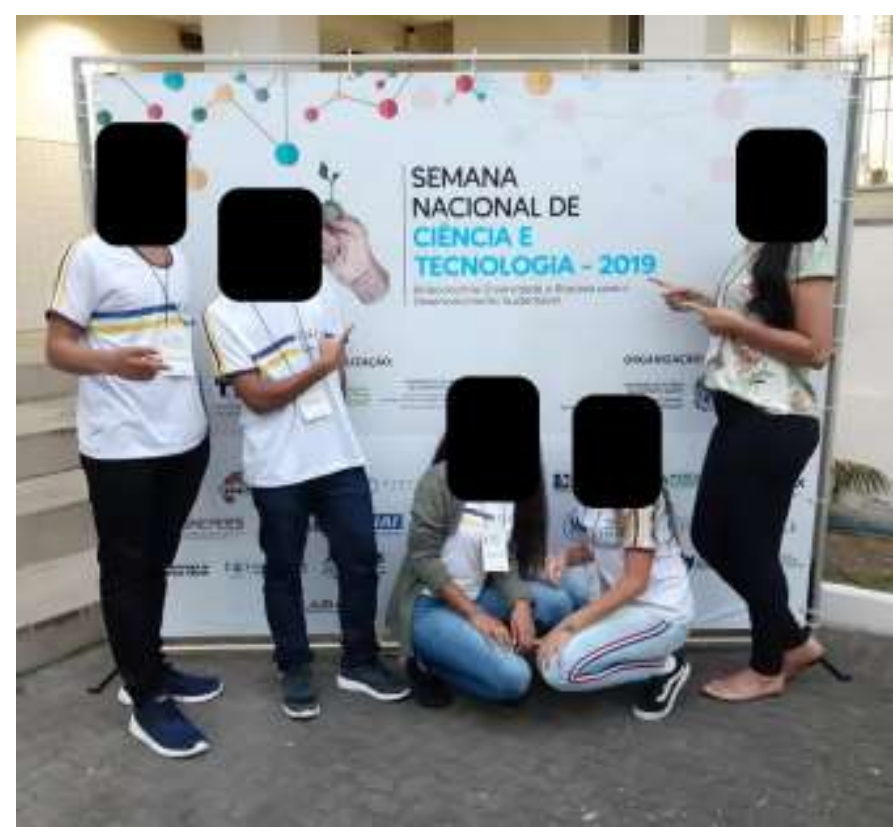

Fonte: Autores (2019).

Durante a realização da feira estadual, um dos avaliadores dos trabalhos é professor do Instituto Federal e por ser engenheiro eletricista gostou da ideia inicial do trabalho e se colocou a disposição para estudar maneiras mais amplas de desenvolver o processo de eletrofloculação e a limpeza da água em outras escolas, até mesmo em algumas comunidades carentes.

\section{Considerações Finais}

Analisando os objetivos propostos nesta atividade, foi possível verificar que a estratégia didática que utiliza atividades experimentais tende a motivar o interesse e a influenciar de maneira positive a aprendizagem dos alunos. Portanto, fica o 
indicativo para que o professor possa destacar em seu planejamento o uso de atividades experimentais potencialmente significativas organizadas a partir do conhecimento prévio do aluno.

A preocupação com os problemas ambientais tem sido crescente no Brasil e no mundo. Na atual situação, a utilização e a reutilização dos recursos naturais fazem parte de uma grande discussão no campo social, econômico e principalmente no campo científico. A Educação Ambiental vem assumindo novas dimensões, efetivando práticas de desenvolvimento sustentável e melhor qualidade de vida para toda sociedade. Por isso, professores e profissionais da educação devem trazer discussões na escola e na comunidade que propiciem a formação de estudantes que apresentem uma nova consciência frente aos problemas ambientais (Silva, 2010).

A experimentação com materiais alternativos permite que os estudantes manipulem objetos e negociem significados entre si, adequando seu uso ao ensino de química para discutir os conceitos da Educação Ambiental. A Educação Ambiental faz parte de uma estratégia fundamental para a formação de indivíduos mais conscientes, solidários e sustentáveis e a escola, é um espaço privilegiado para uma ação efetiva desta atividade. A Educação Ambiental propicia a reflexão referente a questões ambientais, ampliando a visão do indivíduo sem, contudo, perder a dimensão das práticas cotidianas.

A abordagem do professor dos conteúdos escolares na prática de forma contextualizada possibilita a aprendizagem significativa por existir um referencial que permita aos alunos identificar e se identificar com as questões propostas, gerando, assim, a capacidade de compreender e intervir na realidade, numa perspectiva autônoma e desalienante (Moreira \& Masini, 1982).

\section{Referências}

Aljoni-alário, A., \& Wartha, E. J. (2005). A contextualização do ensino de Química através do livro didático. Seção Pesquisa no ensino de Química. Química Nova na Escola, $\mathrm{n}^{\circ} 22$.

Asano, T. (2002). Water from (waste) water - the dependable water resource. Water Science and Technology. 45, 23-33, IWA Publishing.

Ausubel, D. P, Novak, J. D \& Hanesian, H. (1983). Psicología Educativa: un punto de vista cognoscitivo: Trillas.

Barros, J. G. C. (2010). Origem, distribuição e preservação da água no planeta terra. Revista GT Águas, 6(11).

Benite, C. R. M. (2006). Avaliação de Tecnologias Educacionais no Ensino de Química em Nível Médio. Monografia (Especialização no Ensino de Ciências). UFRJ.

Brasil. (1999). Lei $n^{\circ} 9.795$ de 27 de abril de 1999. Dispõe sobre a educação ambiental, institui a Política Nacional de Educação Ambiental e dá outras providências. Brasília.

Carvalho, V. S. (2008). A ética na Educação Ambiental e a ética da Educação Ambiental. In: Machado, C. et al. Educação Ambiental consciente. WAK Editora, 29-46.

Carvalho, D \& Souza, M. A. C. (2015). Utilização do método eletrofloculação para tratamentos de efluentes industriais. Revista Nacional de Gerenciamento de Cidades, 3(14), 14-28.

Carvalho, A. M. (2013). Ensino de Ciências por investigação: condições para implementação em sala de aula. Cengage Learning.

Cerqueira, A. A., \& Marques, M. R. C. (2011) Avaliação do Processo Eletrolítico em Corrente Alternada no Tratamento de Água de Produção. Química Nova na Escola, 34(1), 59 - 63.

Galiazzi, M. C., \& Gonçalves, F. P. (2004). A natureza pedagógica da experimentação: uma pesquisa na licenciatura em química. Química Nova, 27(20, 326331.

Gerhardt, T. E \& Silveira, D. T. (organizadores). (2009). Métodos de Pesquisa. Coordenado pela Universidade Aberta do Brasil - UAB/UFRGS e SEAD/UFRGS. Editora da UFRGS.

Gobbi, L. C. A. (2013). Tratamento de água oleosa por eletrofloculação. Dissertação- Curso de mestrado em Energia, Centro Universitário Norte do Espírito Santo, Universidade Federal do Espírito Santo, São Mateus.

Guimarães, C. C. (2009) Experimentação no ensino de química: caminhos e descaminhos rumo à aprendizagem significativa. Química Nova na Escola; 31(3).

Hodson, D. (1988). Experiments in science and science teaching. Educational Philosophy and Theory, 20(2), 53-66.

Moraes, R, Ramos, M. G., \& Galiazzi, M. C. (2012). Aprender química: promovendo excursões em discursos da química. In: Zanon, L. B.; Maldaner, O. A. (Org.). Fundamentos e propostas de ensino de química para a educação básica no Brasil. Ijuí: Unijuí. 
Research, Society and Development, v. 10, n. 4, e48110414199, 2021

(CC BY 4.0) | ISSN 2525-3409 | DOI: http://dx.doi.org/10.33448/rsd-v10i4.14199

Moreira, M. A. (2012). O Que é Afinal Aprendizagem Significativa? Qurriculum, La Laguna, (25), 29-56.

Moreira, M. A., \& Masini, E. A. F. (1982). Aprendizagem significativa: a teoria de David Ausubel. Editora Moraes.

Neto, A. (2011). Tratamento de resíduos de corante por eletrofloculação: um experimento para cursos de graduação em Química. Química Nova, 34, 14681471

Penin, S.T.S. (2001). Didática e Cultura: O Ensino Comprometido com o Social e a Contemporaneidade. In: Castro, A. D.; Carvalho, A. M. P. (org). Ensinar a Ensinar - Didática para a Escola Fundamental e Média. Pioneira/Thomson.

Penteado, H. D. (2012). Meio ambiente e formação de professores. Cortez.

Silva, A. P. (2009). Educação ambiental em resíduos sólidos nas unidades escolares municipais de Presidente Prudente-SP. 207f. Dissertação (Mestrado em Geografia) - Faculdade de Ciências e Tecnologia, Universidade Estadual Paulista, Presidente Prudente-SP.

Silva, R. R, Machado, P. F. L \& Tunes, E. (2010). Experimentar sem medo de errar. In: Santos, W. L. P.; Maldaner, O. A. (Org.). Ensino de Química em Foco. Ijuí: Unijuí.

Sousa, P. A. A \& Sousa, H. R. (2011). Estimulando o ensino de química através de ilustrações. In: Congresso Brasileiro De Química, 55, 2015, Goiânia. Anais. Goiânia, CBQ

Tundisi, J. G. (2003). Água no século XXI: enfrentando a escassez. (2a ed.), RIMA. 